\title{
ANDES VIRUS ASSOCIATED WITH HANTAVIRUS PULMONARY SYNDROME IN NORTHERN ARGENTINA AND DETERMINATION OF THE PRECISE SITE OF INFECTION
}

\author{
M. GONZALEZ DELLA VALLE, A. EDELSTEIN, S. MIGUEL, V. MARTINEZ, J. CORTEZ, M. L. CACACE, \\ G. JURGELENAS, S. SOSA ESTANI, AND P. PADULA \\ Laboratorio de Hantavirus, Departamento de Virología, Instituto Nacional de Enfermedades Infecciosas INEI, ANLIS Dr. Carlos G. \\ Malbrán, Buenos Aires, Argentina; Hospital San Vicente de Paul, Orán, Salta, Argentina; Laboratorio de Hantavirus, Hospital del \\ Milagro, Salta Capital, Argentina; Centro Nacional de Diagnóstico e Investigación de Endemoepidemiología CeNDIE, ANLIS,
} Buenos Aires, Argentina

\begin{abstract}
Hantavirus pulmonary syndrome (HPS) has been documented in the Salta and Jujuy provinces of northern Argentina since 1991 and 1997, respectively, accounting for almost 50\% of the cases of HPS reported in this country. Andes (AND) virus, specifically the AND virus Nort lineage, was previously associated with human disease in this region. Genetic analysis of viral medium RNA segments obtained from 18 HPS cases showed the existence of three AND virus Nort sublineages co-circulating in these two provinces. They showed a nucleotide sequence diversity of up to $11.1 \%$ between the sublineages. The putative site of infection of one of these cases (Sal3/97) was determined. A $100 \%$ nucleotide sequence identity was observed between the viral sequence found in patient Sal3/97 and in two virus-positive Oligoryzomys chacoensis captured in the same place where the case lived and worked. These results indicated the putative site of infection and identified this rodent species as the source of infection.
\end{abstract}

\section{INTRODUCTION}

Hantaviruses (genus Hantavirus, family Bunyaviridae) are enveloped viruses with three negative-strand RNA segments (small [S], medium [M], and large [L]) coding for a nucleoprotein $(\mathrm{N})$, a glycoprotein precursor (GPC) of two glycoproteins (G1 and G2), and a viral RNA polymerase, respectively. These viruses produce a persistent infection with coexistence of virus and antibodies in their natural reservoirs and are associated primarily with a single rodent species. Human infection occurs mainly after inhalation of infectious aerosols of rodents excreta. ${ }^{1,2}$

The Old World hantaviruses are associated with hemorrhagic fever with renal syndrome (HFRS) and include Hantaan (HTN), Seoul (SEO), and Dobrava (DOB) viruses in Asia and Europe. Nephropatia epidemica (NE) is a mild form of HFRS caused by Puumala (PUU) virus that occurs principally in northern Europe. ${ }^{3}$

Hantavirus pulmonary syndrome (HPS) was first recognized in patients in the United States in 1993 and was associated with Sin Nombre (SN) virus. The major symptoms of this syndrome are fever, myalgia, headache, and gastrointestinal and cardiopulmonary dysfunction with a high case fatality rate.,

An increasing number of hantaviruses associated with human disease have been identified not only in North America, but also in South America (Argentina, Bolivia, Brazil, Chile, Paraguay, and Uruguay, ${ }^{6-8}$ ) and recently in Central America (Panama. ${ }^{9}$ ) Person-to-person transmission was first documented during an outbreak of HPS in southern Argentina in $1996,{ }^{10-12}$ and most likely in two family clusters in Chile in 1997, ${ }^{13}$ all associated with Andes (AND) virus.

From 1995, when the first case of HPS was genetically characterized in Argentina, ${ }^{14}$ through 2000, approximately 320 cases of HPS have been reported in three geographically distinct areas of the country: the southern region (Rio Negro, Chubut, and Neuquén provinces), the central region (Buenos Aires, Entre Rios, and Santa Fe provinces), and the northern region (Salta and Jujuy provinces). Five circulating AND virus lineages associated with human disease have been reported in Argentina: AND Sout and AND Nort in the southern and northern regions of the country, respectively, and
AND Cent Lec, AND Cent Plata, and AND Cent Bs as in the central region. ${ }^{8}$ The results of phylogenetic analysis showed that the hosts of these viruses were most likely Oligoryzomys species. ${ }^{8}$ Maciel (MAC), Pergamino (PRG), and Bermejo (BMJ) viral genotypes associated with two Bolomys obscurus, 14 Akodon azarae, and one Oligoryzomys chacoensis, respectively, have also been identified in Argentina; however, they have not yet been associated with human disease. ${ }^{15}$

Salta is the province in Argentina with the highest number of HPS cases reported per year, except for 1996, when an HPS interhuman transmission event involving 16 cases occurred in the southern part of this country. A high prevalence of hantavirus infection was previously described in Salta, reaching $5 \%$ in the general population (Sosa Estani S and others, unpublished data) and $17 \%$ in an Indian population inhabiting the Salta sector of the Gran Chaco. ${ }^{16}$ Serologic evidence of hantavirus infection in northern Argentina has been found in rodents of the subfamily Sigmodontinae, in $O$. longicaudatus associated with HPS cases in peridomestic rural habitats, and in $O$. chacoensis and A. varius. ${ }^{17}$ However transmission to humans could not be assessed for the last two rodent species since viral genotypes of the animal specimens and the case patient were not available.

To provide more information on the genetic diversity of hantavirus in northern Argentina, we performed a genetic characterization of the circulating virus in 18 HPS cases from this region and determined the complete $S$ segment sequence of the AND virus Nort lineage. We also report the precise site of infection of an HPS case and the identification of a specific rodent species as the source of infection by molecular analysis. Based on the presence of viral RNA and sequencing, we found that AND Nort virus is associated not only with the previously reported $O$. longicaudatus, but also with two other sigmodontine rodents present in this area $(O$. chacoensis and O. flavescens).

\section{MATERIALS AND METHODS}

Human samples and rodent trapping. Sera from 20 patients in northern Argentina obtained between 1997 and 1999 were tested for antibodies to AND viral nucleoprotein (N-AND). 
Whole blood or clots from 18 of the 20 serologically confirmed HPS cases (17 [Sal1/97-Sal5/97, Sal1/98-Sal5/98, Sal1/ 99, Sal 7/99, Sal3/99-SAL5/99, Juj1/98, and Juj1/99] from Salta and Jujuy provinces and one [Neu1/99]) from Neuquén province in southern Argentina) were used to study the viral genetic diversity circulating in the region associated with human disease. Patient samples were obtained between two and 13 days after the onset of the HPS clinical symptoms.

Rodent trapping was carried out in an HPS-endemic area in Salta province during December 1997. Nine households and working places located within $45 \mathrm{~km}$ of the city of Orán were selected for rodent capture. The criteria for the selection of the trapping places were based on previous and recent HPS cases reported in this area. A total of 910 traps, including Sherman and Tomahawk live traps, were used. Closed traps were collected and transported to a field laboratory and were individually processed by personnel wearing biosafety suits with a filtered air supply (HEPA filters). ${ }^{18}$ After animals were anesthesized, blood, lung, and liver tissues were collected and frozen in liquid nitrogen for further studies. Rodent carcasses were stored in a solution of $10 \%$ formalin for one month. Rodent species identification was confirmed at the Museo de Ciencias Naturales (Buenos Aires, Argentina).

Trapping success was calculated as number of captures/ number of trap-nights $\times 100$. Trap-nights were calculated as the number of trap/nights $\times$ the number of nights in the field minus half the number of sprung-but-empty traps encountered. $^{19}$

Serologic screening. Human $\operatorname{IgM}$ and $\mathrm{IgG}$ responses were detected in patient sera using an AND virus-specific enzymelinked immunosorbent assay (ELISA) as previously described. ${ }^{20}$ Briefly, patient and control sera were diluted 1:100 and four fold up to 1:6400. A recombinant AND viral nucleoprotein (N-AND) was used as the specific antigen. For detection of IgM, a $\mu$-capture IgM ELISA was performed using $\mathrm{N}$-AND recombinant antigen and rabbit hyperimmune serum as the second antibody. IgG was detected in rodent sera diluted 1:200 and 1:400 using a peroxidase-labeled affinitypurified antibody to Peromyscus leucopus IgG (heavy plus light chain) as the conjugate. All commercial reagents used were obtained from Kirkegaard and Perry, Inc. (Gaithersburg, MD). ABTS (2, 2'-azino-di [3-ethyl-benzthiazoline sulfonate]) was used as substrate for peroxidase and absorbance was measured at $405 \mathrm{~nm}$. Sera with an optical density $>0.3$ were considered positive.

Preparation of RNA, reverse transcriptase-polymerase chain reaction ( $R T$-PCR) amplification, and sequencing. Total RNA from whole blood or blood clots of HPS patients and from lung tissues of infected rodents was extracted using the guanidinium isothiocyanate-acid phenol extraction procedure as described. ${ }^{14}$ For RNA purification, the RNAid kit (Bio 101) was used following the manufacturer's recommendations. A one-step RT-PCR was performed followed by a second round of nested or heminested PCR. For the amplification and sequencing of the complete $S$ and partial M AND virus segments, specific oligonucleotide primers were used as described. ${ }^{12,21}$

An additional minus primer 5'-TAGTAGTATGCTCCTTG-3' (nucleotides 1860-1876 numbered related to AND virus) was used for the $5^{\prime}$ non-coding region of the $\mathrm{S}$ segment. The PCR products were separated by electrophoresis on agarose gels, gel purified (Wizard PCR preps; Promega, Madi- son, WI), and sequenced using the dideoxy cycle sequencing technique (fmol DNA Sequencing System; Promega) or the ABI PRISM Big Dye Terminator Sequencing kit (PerkinElmer Applied Biosystems Division, Foster City, CA). Reactions were performed on a Perkin-Elmer GeneAmp PCR System 2400. All the amplified and sequenced fragments were numbered in the antigenome sense.

Phylogenetic analysis. Phylogenetic trees were performed using the PHYLIP package (version $3.57 \mathrm{c}$ ). ${ }^{22}$ The percentage of bootstrap supporting each node was indicated at branch points with values greater than $50 \%$ and was obtained from 500 replicates (SEQBOOT) (CONSENSE). DNAPARS was used to obtain maximum parsimony trees. The lengths of the tree stems were proportional to genetic distances obtained using DNADIST program-weighting transversion twice as transition. The FITCH program was used to fit distances to maximum parsimony trees. Horizontal distances indicate approximate nucleotide sequence percentage differences between virus variants.

For the phylogenetic analysis of the complete S segment, known sequence data were obtained from GenBank. The complete S segment sequences included Seoul (SEO) virus Genbank accession number AB027522, Hantaan (HTN) virus U37768, Rio Segundo (RIOS) virus U18100, Prospect Hill (PH) virus Z49098, Puumala Sotkamo (PUU) virus X61035, Sin Nombre (SN) virus L37904, New York (NY) virus U09488, Black Creek Canal (BCC) virus L39949, Bayou (BAY) virus L36929, Rio Mamore (RIOM) virus U52136, Laguna Negra (LN) virus AF005727, Andes virus (AND Sout) strain AH-1 AF004660, and AND Nort virus AF325966, reported in this study. For the phylogenetic analysis of the M segment, three fragments were used: 1) a 194nucleotide fragment (nucleotides 88-281) including Sal3/97 (Genbank accession number AF389483), AND Cent Bs As 1/98 (AF389484), AND Cent Plata 2/97 (AF389485), AND Cent Lec 1/98 (AF389486), and AND Sout 1/95 (AF389487); 2) a 252-nucleotide fragment (nucleotides 1736-1987) including Sal3/97 (AF389491), AND Cent Bs As 1/98 (AF389490), AND Cent Plata 2/97 (AF389488), AND Cent Lec 1/98 (AF389489), and AND Sout 1/95 (AF389492); and 3) a 226nucleotide fragment (nucleotides 2721-2946) including Sal1/ 97 (AF389512), Sal2/97 (AF389499), Sal3/97 (AF389502), Sal4/97 (AF389495), Sal5/97 (AF389498), Sal1/98 (AF389510), Sal2/98(AF389501), Sal3/98 (AF389493), Sal4/98 (AF389500), Sal5/98 (AF389511), Sal1/99 (AF389494), Sal3/ 99 (AF389497), Sal4/99 (AF389503), Sal5/99 (AF389508), Sal7/99 (AF389496), Juj1/98 (AF389506), Juj1/99 (AF389509), Neu1/99 (AF389507), O. chacoensis \#27/97 and O. chacoensis \#30/97 (AF389504), O. flavescens \#34/97 (AF389505), AND Cent Bs As 1/98 (AF389482), AND Cent Plata 2/97 (AF389479), AND Cent Lec 1/98 (AF389480), and AND Sout 1/95 (AF389481).

\section{RESULTS}

Epidemiologic data and presentation of cases. Hantavirus pulmonary syndrome was first reported in southern Argentina in 1995 and subsequently in the central and northern regions of this country. Almost $50 \%$ of the cases of HPS in Argentina have occurred in the northern region, with the majority in Salta (120 cases since 1995) and in less in Jujuy (46 cases from 1997 through 2000). Subtropical vegetation with 
forests and jungles predominates in this region. The two principal agricultural activities are the growing of sugar cane and citrus fruits. Deforestation is essential for these activities. Thus, there is an interaction between workers and the wild fauna in this location, which results in an increase in the possibility of acquiring HPS or other zoonotic diseases. The number of cases of HPS in Salta has increased annually since 1995, reaching 35 in 1997 and decreasing to 29 in 1998, 22 in 1999, and 15 in 2000 , with mortality rates of $23 \%, 7 \%, 24 \%$, and $27 \%$, respectively. It is important to note when comparing mortality rates in Salta with those in other areas of the country that the same physician from the intensive care unit of the San Vicente de Paul Hospital in Orán (Salta province) has been treating patients with respiratory distress since 1985. The highest occurrence of HPS cases in this province is in the fall (March-June) and spring (September-December) (Figure 1). As noted in this figure, an increase in cases of HPS (9 of 35) was observed during November and December 1997. The number of cases subsequently decreased and the peaks in the fall and spring of 2000 were not as pronounced.

Twenty cases of suspected HPS in Salta and Jujuy provinces between 1997 and 1999 were included in the present study. Initial samples were obtained between two and 13 days after the beginning of symptoms. Specific IgM antibodies to $\mathrm{N}$-AND virus were detected in the initial samples of 19 patients. An IgG response was detected in the initial samples of 18 patients. An IgM response could not be detected in the initial sample of one case two days after the onset of symptoms; however, test results for IgG antibodies and the RTPCR were positive. Subsequent samples were not available for the IgM-negative patients or the two IgG-negative patients. Viral RNA was isolated from the initial samples of 18 of the 20 patients and subjected to molecular analysis.

Genetic characterization of circulating virus in humans. Viral RNA isolated from 18 of the 20 HPS cases was used in a detailed genetic characterization of the circulating virus in the study areas. A 226-nucleotide fragment (nucleotides 27212946) of the viral M segment obtained from these patients was analyzed by RT-PCR and sequenced. Pairwise nucleotide comparison showed that all 18 patients were infected with AND virus, specifically the AND virus Nort lineage. These viral sequences showed a sequence diversity up to $11.1 \%$ and

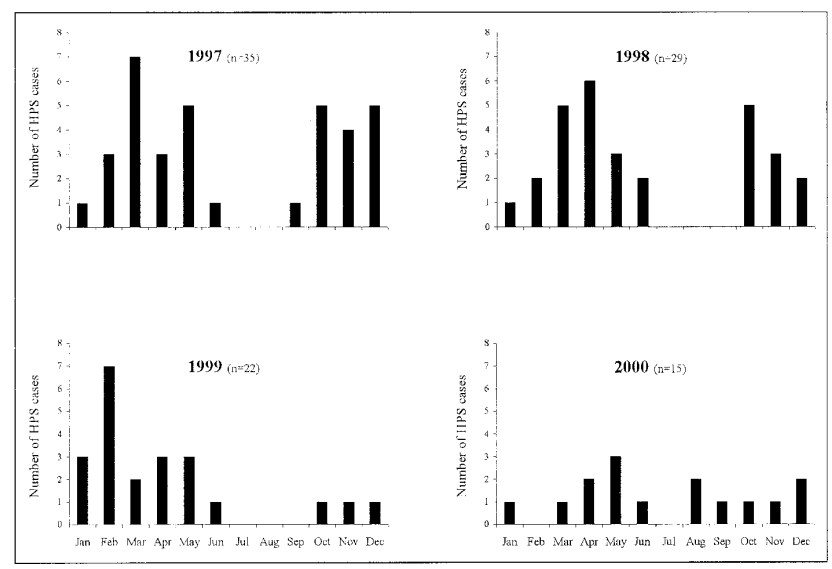

FIGURE 1. Number of hantavirus pulmonary syndrome (HPS) cases per month during the period 1997-2000 in the Salta province of northern Argentina. a highly conserved amino acid sequence (Table 1). Based on sequence similarities of this partial G2 fragment, three genetic viral sublineages could be distinguished among the studied patients. One sublineage included the two cases from Jujuy (Juj1/98, Juj1/99) and one case from Salta (Sal5/99) located close to the border with Jujuy. The other 14 cases, located at least $50 \mathrm{~km}$ north of Jujuy, formed two different sublineages and included three cases (Sal1/97, Sal1/98, and Sal5/98) in one sublineage and 11 (Sal2/97-Sal5/97, Sal2/98-Sal4/98, Sal1/99, Sal7/99, Sal3/99, and Sal4/99) in the other sublineage. The nucleotide sequence diversity between these two sublineages and the Jujuy viral sequences ranged from $5.8 \%$ to $8.4 \%$ and $5.3 \%$ to $9.3 \%$, respectively. The two sublineages from Salta were observed within $45 \mathrm{~km}$ of Orán and co-circulated without geographic clustering (Figure 2). The nucleotide sequence diversity between these two sublineages ranged from $7.1 \%$ to $11.1 \%$. The maximal nucleotide variation found within each of the three sublineages ranged from $3.5 \%$ to $5.3 \%$. During the study period (1997-1999), minor genetic variation was observed within each sublineage in the viral region analyzed. In addition, a sample from a 23-year-old man (Neu1/99) from Neuquén province (southern Argentina) was also included in this report. After working for one month in Salta province, this case returned to Neuquen where the onset of symptoms of HPS occurred 15 days after his arrival. Nucleotide sequence comparison of the same partial G2 fragment obtained from this patient showed the highest degree of identity with sequences from Jujuy (between $96.5 \%$ and $97.3 \%$ ) and a nucleotide sequence identity of $85.4 \%$ compared with the circulating AND virus in southern Argentina (AND Sout lineage).

Trapping and viral genetic characterization in rodents. Rodent capture was carried out in nine different locations within $45 \mathrm{~km}$ of Orán (Salta province) during December 1997. The trapping areas were selected based on previous and recent HPS case reports. Thirty-nine rodents were captured: six Oligoryzomys species, eight $O$. chacoensis, one $O$. longicaudatus, two O. flavescens, one Akodon varius, one Calomys species, nine $C$. callosus, four Rattus rattus, three Eligmodontia typus, and three Bolomys lasiurus; one rodent was not identified. The trapping success rate was $4.9 \%$. Oligoryzomys genus was the most frequently obtained (17 of 39). All trapped rodents were tested for IgG antibodies to N-AND by ELISA. Four specimens were positive: two O. chacoensis (\#27/97 and \#30/ 97), one O. flavescens (\#34/97), and one A. varius (\#31/97). The four serologically positive rodents were trapped in the same place where a recent HPS human case (Sal3/97) had resided and worked. Interestingly, $O$. chacoensis was the rodent species most frequently captured in this location (7 of 16). Partial amplimers of $S$ and $M$ viral segments were obtained from the three antibody-positive Oligoryzomys and sequenced. Genetic analysis based on 288 nucleotides of the nucleoprotein (nucleotides 49-336), 250 nucleotides of G1 (nucleotides 1735-1984), and 226 nucleotides of G2 (nucleotides 2721-2946) showed a 100\% nucleotide sequence identity between each of the two $O$. chacoensis viral sequences and nucleotide sequence divergences of $1.0 \%$ and $1.7 \%$ in the $\mathrm{S}$ and $\mathrm{M}(\mathrm{G} 1+\mathrm{G} 2)$ segments, respectively, when compared with the viral sequences from $O$. flavescens. No positive RTPCR results were obtained with $A$. varius. Eight additional serologically negative captured rodents (one O. longicaudatus, three $O$. chacoensis, three $C$. callosus, and one $O$. flave- 


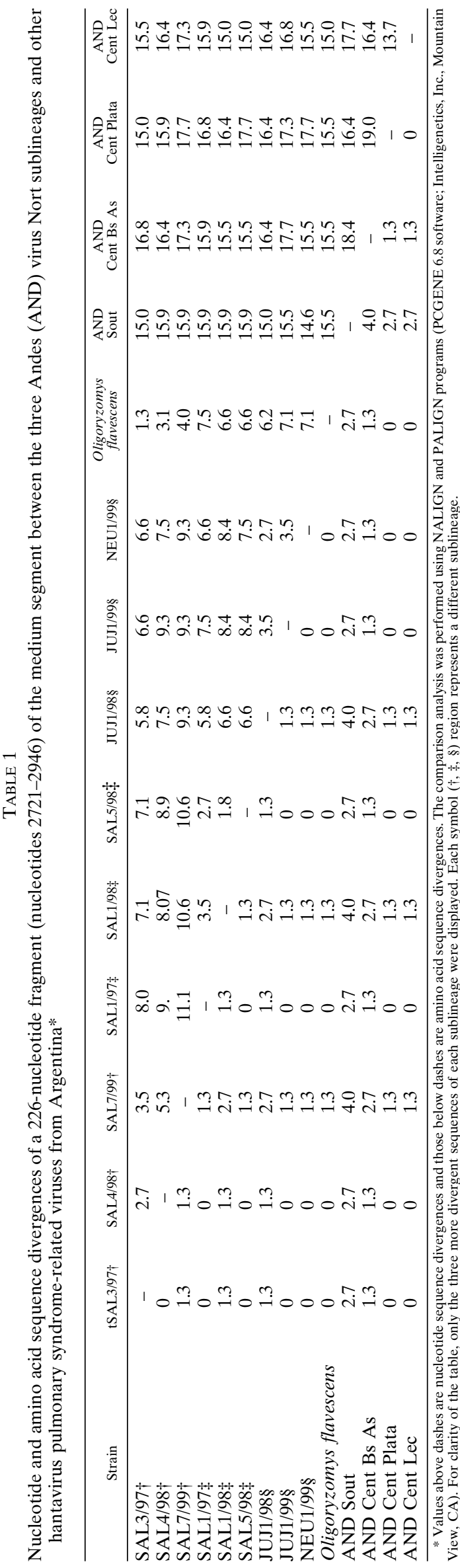

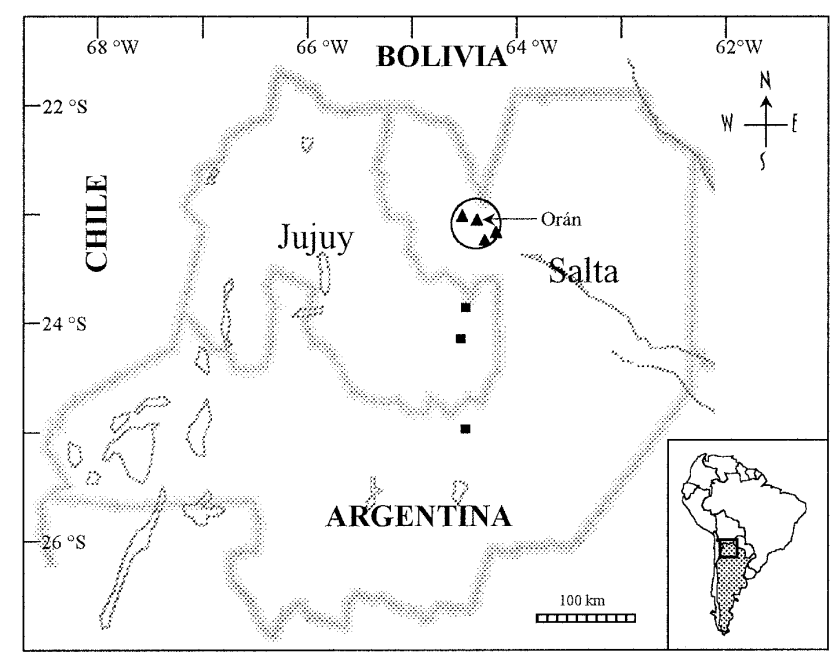

FIGURE 2. Location of hantavirus pulmonary syndrome (HPS) cases in Salta and Jujuy provinces in northern Argentina. $(\boldsymbol{\Lambda})=$ the HPS cases associated with the two Andes (AND) Nort viral sublineages co-circulating in Salta. $(\boldsymbol{\square})=$ HPS cases associated with the AND Nort viral sublineage from Jujuy. The circle indicates the rodent trapping area.

scens) were screened for AND viral RNA. All eight tested negative by the RT-PCR.

Determination of the putative site of infection of a case of HPS. In 1997, 35 (28 males and 7 females) of 57 HPS cases reported in Argentina were identified in Salta. During December of that year, five HPS cases (Sal3/97 to Sal7/97, 3 males and 2 females) were reported in this province, each one in a different locality around Orán. They were all treated at the San Vicente de Paul Hospital in Orán. One of the five patients (a female) died of acute respiratory failure. Another patient (Sal3/97), a 40-year-old man, worked in a deforestation camp in Carmelita near Orán. He also lived near the camp under very precarious conditions. The four serologically positive rodents obtained during the 1997 capture were trapped in the camp where this case of HPS resided and worked eight days after he showed the onset of symptoms. Comparison of the 288- and 476-nucleotide sequences of the $\mathrm{S}$ and $\mathrm{M}$ segments, respectively, showed an identity of $100 \%$ between the viral sequences found in patient Sal3/97 and in the two virus-positive specimens characterized from $O$. chacoensis. The viral sequences obtained from $O$. flavescens showed three silent mutations (divergence $=1.0 \%$ ) and eight silent mutations (divergence $=1.7 \%$ ) at the nucleotide level in the $\mathrm{S}$ and $\mathrm{M}$ segments, respectively, compared with the human case. Further assessment of a genetic relationship between the virus characterized from patient Sal3/97 and both characterized from $O$. chacoensis (409 nucleotides of G1 [nucleotides 52-460]) showed $100 \%$ homology. Total identity was also observed between $O$. chacoensis \#27/97 and Sal3/97 viral sequences in 277 nucleotides (nucleotides 660-936) from the coding region and in 394 nucleotides (nucleotides 14241817) from the non-coding region of the S segment, respectively. These results suggest that $O$. chacoensis was the source of infection and the camp in Carmelita as the putative site of infection.

To study the genetic variability of the virus circulating in this area, two additional cases, Sal4/97 and Sal5/97, which occurred close to the putative site of infection of Sal3/97, were 
analyzed. Nucleotide sequence comparison of a 476nucleotide region of the $\mathrm{M}$ segment showed a divergence of $1.1 \%$ and $2.1 \%$, respectively, when compared with the $O$. chacoensis viral sequence. A total identity at the amino acid level was maintained. Samples from serologically positive cases Sal6/97 and Sal7/97 were not available for molecular amplification and analysis.

Complete nucleotide sequence of the $S$ segment of the AND virus Nort lineage. The complete $S$ segment of AND Nort virus was amplified and sequenced from lung tissue of $O$. chacoensis \#27/97. It consisted of 1,911 nucleotides coding for a 428-amino acid nucleocapsid protein with an open reading frame (ORF) at position 43 and a stop codon at position 1327. Terminal nucleotides (16 nucleotides at the $3^{\prime}$ end and 17 nucleotides at the $5^{\prime}$ end) were assumed to be present based on the primer sequences used for amplification and sequencing of the S segment. Similar to other Sigmodontinae-borne hantaviruses, an additional ORF coding for a putative nonstructural protein of 63 amino acids was found at position 122 . Four cysteine residues were present at positions 203, 244, 309, and 314 , consistent with the nucleocapsid protein sequences of other pulmonary-related hantaviruses. The eightnucleotide motif $5^{\prime}$-CTACCTCA-3' was found three times at positions 1826,1854 , and 1872 . The $5^{\prime}$ non-coding region of 581 nucleotides was shown to be 45 and seven nucleotides longer than those in AND Sout and LN viruses, respectively, and 64 and 149 nucleotides shorter than those in RIOM and $\mathrm{SN}$ viruses, respectively. Nucleotide and amino acid sequence comparison of the AND Nort virus coding S segment showed $83.6 \%$ and $96.5 \%$ identity, respectively, and almost $78 \%$ identity in the $5^{\prime}$ non-coding region, when compared with the AND Sout virus. The identity of the AND Nort virus S segment with other pulmonary-related hantaviruses circulating in America was lower: $78.9 \%$ and $89.9 \%$ with $\mathrm{LN}$ virus, $81 \%$ and $90.4 \%$ with RIOM virus, and $76.9 \%$ and $86.7 \%$ with SN virus at the nucleotide and amino acid sequence levels, respectively.

Phylogenetic analysis. Maximum parsimony analysis based on sequences of the entire S segment was carried out using a 2:1 weighting of transversion over transition (Figure 3). Within the Sigmodontinae-associated viruses, South American hantaviruses formed a well-supported clade ( $90 \%$ bootstrap support) separated from the North American BAY and BCC viruses. The AND Nort virus appeared as a monophyletic group with AND Sout virus with a well-supported bootstrap value (100\%). Moreover, LN virus from Paraguay and RIOM virus from Bolivia formed a monophyletic clade with AND viral lineages. A similar tree topology was observed for a partial M segment. ${ }^{8}$

To better appreciate the level of genetic diversity of the AND Nort virus sequences, a maximum parsimony analysis based on nucleotide sequences of three M-segment PCR fragments (nucleotides 88-281 and 1736-1987 of G1 and nucleotides 2721-2946 of G2) was included (Figure 4). The virtually identical Sal3/97 and O. chacoensis \#27/97 sequences were selected as being representative of the AND virus Nort lineage. The inset in Figure 4 shows the phylogenetic relationship among the 226-nucleotide sequence of the M segment (nucleotides 2721-2946) amplified from the 18 HPS cases and the rodents (two $O$. chacoensis and one $O$ flavescens) captured in Salta in 1997. The estimated phylogeny of the three AND virus Nort sublineages was compatible with

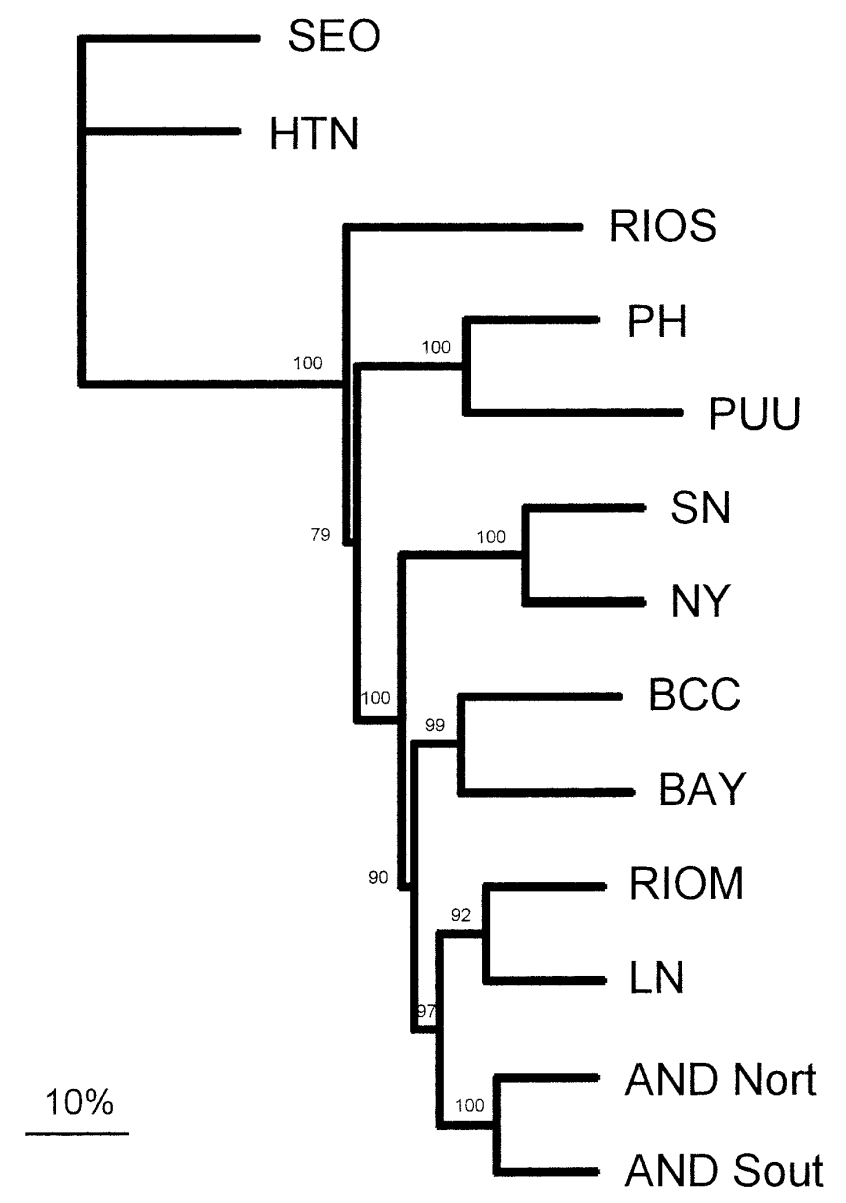

FIGURE 3. Phylogenetic analysis of the entire Andes virus Nort small segment (GenBank accession number AF325966) obtained from one Oligoryzomys chacoensis and previously characterized hantaviruses. SEO = Seoul $($ AB027522); HTN = Hantaan $($ U37768); RIOS = Rio Segundo (U18100); PH = Prospect Hill (Z49098); PUU $=$ Puumala Sotkamo (X61035); SN = Sin Nombre (L37904); NY = New York (U09488); BCC = Black Creek Canal (L39949); BAY = Bayou (L36929); RIOM = Rio Mamore (U52136); LN = Laguna Negra (AF002757); AND Nort = Andes Nort (AF325966); AND Sout $=$ Andes AH-1 (AF004660).

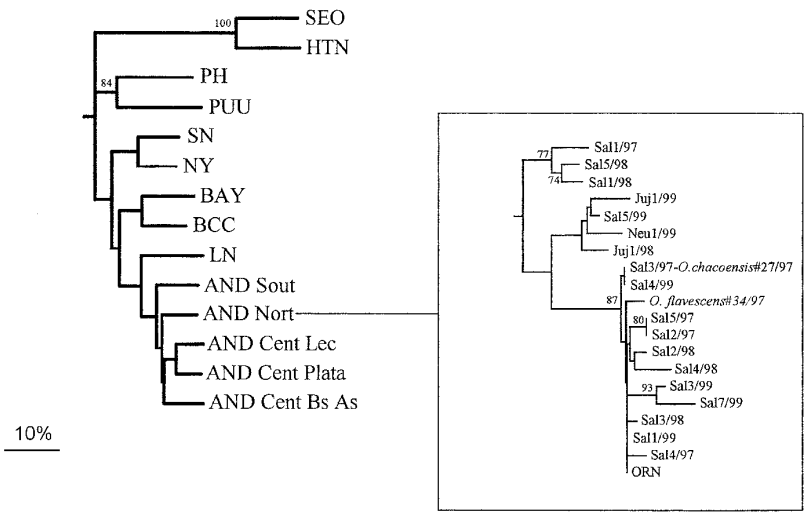

FIGURE 4. Phylogenetic analysis based on nucleotide sequences of three medium (M) segment polymerase chain reaction fragments (nucleotides 88-281 and 1736-1987 of G1 and nucleotides 2721-2946 of G2). The phylogenetic tree is based on the partial M segment (nucleotides 2721-2946 of G2) of the Andes (AND) virus Nort sublineages in the inset. For definitions of other abbreviations, see Figure 3 . 
the three sublineages distinguished by nucleotide pairwise comparisons. The phylogenetic tree constructed using this fragment was poorly resolved at one branch point (50\% bootstrap value). A neighbor-joining analysis of the same data resulted in a similar tree topology, but this did not help to improve the resolution of the tree. The complexity of the South American hantavirus phylogenetic studies as previously suggested again shows the difficulty in the analysis of molecular phylogeny, ${ }^{7}$ especially when small nucleotide fragments are used.

\section{DISCUSSION}

Argentina has the highest number of reported cases of HPS in South America, with approximately 320 confirmed cases from 1995 through 2000 in the three geographic regions previously mentioned (southern, central, and northern). The mortality rate has decreased from $70 \%$ in the first outbreaks to $30 \%$ in more recent outbreaks. Salta and Jujuy provinces constitute an HPS-endemic region with an occurrence of cases mostly during autumn and spring. Retrospective studies indicate that the first HPS case in Salta was reported in 1991. Since then, hantavirus has been a health public concern in Argentina. Because of the high occurrence of HPS cases reported in the northern region of this country, we sought to 1) genetically characterize in greater detail the virus associated with HPS in northern Argentina, 2) genetically characterize the host in which the virus circulated in Salta, and 3) identify the putative site of infection of HPS and the associated risk factors.

Based on our data of partial viral sequences obtained from 18 HPS cases infected in Salta and Jujuy provinces, we proposed the existence of at least three AND virus Nort sublineages. In a previous study, we found that similarities among viral nucleotide sequences of a unique AND lineage in a partial G2 fragment (position 2721-2946) were between 90\% and $100 \%{ }^{8}$ The criteria used to separate the viruses into their respective sublineages in the present report was based on the same partial G2-encoding fragment. A maximal nucleotide variation between $3.5 \%$ and $5.3 \%$ was observed within each sublineage. Maximum parsimony analysis confirmed these results, grouping each of the three sublineages into three separate clusters and in the same clade with other AND lineages. A larger fragment of the viral genome would help to assess this criteria. However, geographic distribution of each of the three sublineages could not be observed. Moreover, the two sublineages from Salta co-circulated within a $50-\mathrm{km}$ radius. An extensive viral analysis including more HPS cases could help in assessing geographic clustering.

The wide distribution of AND virus and the presence of five AND lineages circulating in Argentina, three in the central region (AND Cent Bs As, AND Cent Plata, and AND Cent $\mathrm{Lec}$ ), one in the northern region (AND Nort), and one in the south region (AND Sout), raise the possibility of the existence of more than one rodent species as a natural reservoir. To date, the sigmodontine rodent $O$. longicaudatus is accepted as the natural reservoir of AND Sout virus in southern Argentina. Viral RNA was previously recovered from two O. longicaudatus captured in Salta province and was associated with an HPS case from that region, with a partial M segment nucleotide sequence identity of $98.6 \%$. Based on this data, $O$. longicaudatus was associated with the hantavirus associated with human disease in northern Argentina. ${ }^{15}$ In the present study, we reported the presence of AND Nort viral RNA in two O. chacoensis and one $O$. flavescens. Both rodent species were captured in the same place in which human case Sal3/97 had lived and worked, and were genetically associated with the virus characterized from this case, showing a high nucleotide sequence homology in both the $\mathrm{S}$ and $\mathrm{M}$ viral segments. In addition, 41\% (16 of 39) of the rodents we obtained in the entire capture procedure were trapped in this camp and seven of the eight $O$. chacoensis were recovered at this location. Due to the low number of infected rodents captured, we did not identify either of these two rodent species as the natural reservoir of AND Nort virus. However, the high proportion of $O$. chacoensis captured in this camp and the identity between the viral sequence found in this rodent species and in case Sal3/97 provide strong evidence that $O$. chacoensis was the source of infection and should be considered as the putative reservoir of AND Nort virus. In addition, only one $O$. longicaudatus was captured at this location, and antibodies to AND virus or viral RNA were not obtained from this specimen. The identity in the viral sequences of the rodent and the HPS case also confirmed the site of infection. This is the first report of identical viral sequences found in an HPS case and a natural rodent host in northern Argentina.

In addition to the three serologically positive Oligoryzomys (two $O$. chacoensis and one $O$. flavescens) captured in the camp at Carmelita, antibodies to AND virus were detected in one $A$. varius. The fact that the four serologically positive rodents were trapped in the same place and that there are no reports of AND Nort viral RNA detected in Akodon species, indicates that the presence of antibodies to AND virus in $A$. varius could be attributed to an spillover event. Moreover, previous studies have reported the presence of viral antibodies in A. varius captured in northern Argentina. ${ }^{15}$

In addition to the AND viral lineages associated with human disease, other hantaviruses not associated with HPS have been reported in Argentina (e.g., BMJ virus, MAC virus, and PRG virus). Bermejo virus, which has a different hantavirus genotype, was associated with one $O$. chacoensis captured in Orán, Salta. ${ }^{15}$ Interestingly, nucleotide and amino acid sequence divergences of $17.4 \%$ and $4.4 \%$ in a 476 -nucleotide region of the $\mathrm{M}$ segment were observed between the viral sequence recovered from both $O$. chacoensis associated with AND Nort virus and the BMJ virus sequence previously reported in $O$. chacoensis.

The significance of these findings is consistent with the difficulty of demarcating individual virus species within the genus Hantavirus, especially in South America. To data, the criteria for designating what constitutes a novel hantavirus (species) have been inconsistent and arbitrary. ${ }^{23}$ The presence of viral RNA of a single hantavirus in other rodent species besides the natural reservoir was previously described in North America, but with a low incidence. ${ }^{24}$ Sin Nombre viral RNA was found not only in its primary reservoir (Peromyscus maniculatus), but also in $P$. truei and $P$. boylii and in species from other families of rodents such as Neotoma albigula and N. lepida. ${ }^{25}$

Recent studies have suggested that based on rodent mitochondrial DNA sequence differences, viral genetic variants could be associated with different species of Peromyscus and even in some cases with phylogenetically distinct subspecies 
or mitochondrial DNA haplotypes. ${ }^{26}$ Our data may be useful in understanding that closely related AND HPS-associated hantaviruses such as AND Nort and AND Sout, with a partial G1 plus G2 amino acid identity of $92.3 \%$, could be found in O. longicaudatus. $^{8}$ However, it would be important to define serotypic relationships among these viruses to establish common neutralization determinants. In addition, proper rodent taxonomy will be necessary for analysis of co-speciation and phylogenetic relationships among human hantaviruses isolated in Argentina and their respective rodent hosts.

There is limited knowledge on the distribution of hantavirus in Salta and the risk for exposure within this endemic region. Previous studies associated the presence of infected O. longicaudatus with HPS cases in peridomestic rural habitats. ${ }^{17} \mathrm{We}$ addressed the question of whether rodents captured close to households with HPS were identical or different species. Outbreaks usually appear to be positively associated with rodent population densities, which in turn are correlated with climatic change and land use patterns by humans. However, the high seroprevalence observed in the region studied and the high number of cases reported annually is not consistent with the distribution of infected Oligoryzomys obtained in the rodent capture throughout this region. As shown in Figure 1, an unusual increase in the number of HPS cases in Salta during November and December 1997 was rarely observed. The genetic diversity found in the circulating virus and the number of virus-positive rodents captured do not explain this phenomenon. The viral sequences obtained from HPS cases reported during this period (Sal3/97, Sal4/97, and Sal5/97) belong to the same AND Nort viral sublineage as those characterized from the captured rodents (both $O$. chacoensis and $O$. flavescens).

Many agricultural workers live in areas adjacent to the fields during the work period and are more exposed to rodents and their excreta. The risk for the acquisition of HPS could be reduced by avoiding living and working in the same place if wild rodents are present in the area. Thus, it is important to consider this factor when addressing the interaction between the workers in the specific areas and wild rodents.

In conclusion, we report the existence of three sublineages among AND Nort viruses obtained from 18 HPS cases, two $O$. chacoensis, and one $O$. flavescens. We believe that the number of infected rodents captured was insufficient to postulate a specific Olygoryzomys species as the natural reservoir for the AND Nort viral lineage, but the existence of AND Nort viral sequences in three Oligoryzomys species is evidence that this genus may be the putative reservoir of this virus in northern Argentina. These findings, along with additional studies, could be used to identify environmental factors associated with high risk of hantavirus exposure in northern Argentina.

Acknowledgments: We thank the clinics, physicians, especially Dr. Pedro Alberto Cortada, and health care workers in Oran for patient care; Dr. Martha Piantanida (Museo de Ciencias Naturales, Buenos Aires) for identifying the rodent specimens; and Natalia Pereyra and Octavio Fusco for performing the DNA sequencing and technical support.

Authors' addresses: M. Gonzalez Della Valle (telephone/fax: 54-114301-3146, E-mail: ppadula@cvtci.com.ar), A. Edelstein, S. Miguel, V. Martinez, and P. Padula, Laboratorio de Hantavirus, Departamento de Virología, Instituto Nacional de Enfermedades Infecciosas
INEI, ANLIS Dr. Carlos G. Malbrán, Buenos Aires, Argentina. J. Cortez, and M. L. Cacace, Hospital San Vicente de Paul, Orán, Salta, Argentina. G. Jurgelenas, Laboratorio de Hantavirus. Hospital del Milagro, Salta Capital, Argentina. S. Sosa Estani, Centro Nacional de Diagnóstico e Investigación de Endemoepidemiología CeNDIE, ANLIS, Buenos Aires, Argentina.

\section{REFERENCES}

1. Elliot RM, Schmaljhon CS, Collet MS, 1991. Bunyavirus genome structure and gene expression. Curr Top Microbiol Immunol 169: 91-141.

2. Plyusnin A, Vapalahti O, Vaheri A, 1996. Hantavirus: genome structure, expression and evolution. J Gen Virol 77: 2677-2687.

3. Lee JS, 1999. Clinical manifestation and treatment of HFRS and HPS. Lee WH, Calisher CH, Schmaljohn C, eds. Manual of Hemorrhagic Fever with Renal Syndrome and Hantavirus Pulmonary Syndrome. Seoul: World Health Organization Collaborating Center for Virus Reference and Research (Hantaviruses). Asian Institute for Life Sciences 18-27.

4. Nichol ST, Spiropoulou CF, Morzunov S, Rollin PE, Ksiazek TG, Feldmann H, Sanchez A, Childs J, Zaki S, Peters CJ, 1993. Genetic identification of a hantavirus associated with an outbreak of acute respiratory illness. Science 262: 914-917.

5. Duchin J, Koster F, Peters CJ, Simpson GL, Tempest B, Zaki SR, Ksiazek TG, Rollin PE, Nichol S, Umland ET, Moolenaar RL, Reef SE, Nolte KB, Gallaher MM, Butler JC, Breiman RF, Hantavirus Study Group, 1994. Hantavirus pulmonary syndrome: a clinical description of 17 patients with a newly recognized disease. $N$ Engl J Med 330: 949-955.

6. Johnson AM, Bowen MD, Ksiazek TG, Williams RJ, Bryan RT, Mills JN, Peters CJ, Nichol ST, 1997. Laguna Negra virus associated with HPS in Western Paraguay and Bolivia. Virology 238: $115-127$.

7. Johnson AM, de Souza LTM, Ferreira IB, Pereira LE, Ksiazek TG, Rollin PE, Peters CJ, Nichol ST, 1999. Genetic investigation of novel hantaviruses causing fatal HPS in Brazil. $J$ Med Virol 59: 527-535.

8. Padula PJ, Colavecchia SB, Martínez VP, Gonzalez Della Valle MO, Edelstein A., Miguel SDL, Russi J, Mora Riquelme J, Colucci N, Almirón M, Rabinovich RD, 2000. Genetic diversity, distribution and serologic features of hantavirus infection in five countries in South America. J Clin Microbiol 38: 30293035.

9. Vincent MJ, Quiroz E, Gracia F, Sanchez AJ, Ksiazek TG, Kitsutani PT, Ruedas LA, Tinnin DS, Caceres L, Garcia A, Rollin PE, Mills JN, Peters CJ, Nichol ST, 2000. Hantavirus pulmonary syndrome in Panama: identification of novel hantaviruses and their likely reservoirs. Virology 277: 14-19.

10. Enria D, Padula P, Segura EL, Pini N, Edelstein A, Riva Posse C, Weissenbacher MC, 1996. Hantavirus pulmonary syndrome in Argentina. Possibility of person-to-person transmission. $\mathrm{Me}$ dicina (B Aires) 56: 709-711.

11. Wells RM, Sosa Stani S, Yadón ZE, Enria D, Padula P, Pini N, Mills JN, Peters CJ, Segura EL, the Hantavirus Pulmonary Syndrome Study Group for Patagonia, 1997. An unusual hantavirus outbreak in southern Argentina: person-to-person transmission? Emerg Infect Dis 3: 171-174.

12. Padula PJ, Edelstein A, Miguel SDL, López NM, Rossi CM, Rabinovich RD, 1998. Hantavirus pulmonary syndrome outbreak in Argentina: molecular evidence for person-to-person transmission of Andes virus. Virology 241: 323-330.

13. Toro J, Vega JD, Khan AS, Mills JN, Padula PJ, Terry W, Yadón Z, Valderrama R, Ellis BA, Pavletic C, Cerda R, Zaki S, WunJu S, Meyer R, Tapia M, Mansilla C, Baro M, Vergara JA, Concha M, Calderón G, Enria D, Peters CJ, Ksiazek TG, 1998. An outbreak of hantavirus pulmonary syndrome, Chile, 1997. Emerg Infect Dis 4: 687-694.

14. López N, Padula P, Rossi C, Lázaro ME, Franze-Fernández MT, 1996. Genetic identification of a new hantavirus causing severe pulmonary syndrome in Argentina. Virology 220: 223-226.

15. Levis S, Morzunov S, Rowe J, Enria DA, Pini N, Calderon G, Sabattini M, St. Jeor SC, 1998. Genetic diversity and epidemiology of hantaviruses in Argentina. J Infect Dis 177: 529-538. 
16. Ferrer JF, Jonsson CB, Esteban E, Galligan D, Basombrio MA, Peralta-Ramos M, Bharadwaj M, Torrez-Martinez N, Callahan J, Segovia A, Hjelle B, 1998. High prevalence of hantavirus infection in Indian communities of the Paraguayan and Argentinean Gran Chaco. Am J Trop Med Hyg 59: 438-444.

17. Calderon G, Pini N, Bolpe J, Levis S, Mills J, Segura E, Guthmann N, Cantoni G, Becker J, Fonollat A, Ripoll C, Bortman M, Benedetti R, Sabattini M, Enria D, 1999. Hantavirus reservoir hosts associated with peridomestic habitats in Argentina. Emerg Infect Dis 5: 792-797.

18. Mills JN, Childs JE, Ksiazek TG, Peters CJ, Velleca WM, 1995. Methods for Trapping and Sampling Small Mammals for Virologic Testing. Atlanta, GA: U.S. Department of Health and Human Services, Center for Disease Control and Prevention.

19. Mills JN, Ellis BA, McKee KT, Maiztegui JI, Childs JE, 1991 Habitat associations and relative densities of rodent populations in cultivated areas of central Argentina. J Mammalogy 72: 470-479.

20. Padula PJ, Rossi CM, Della Valle MO, Martínez VP, Colavecchia SB, Edelstein A, Miguel SDL, Rabinovich RD, Segura EL, 2000. Development and evaluation of a solid phase enzyme immunoassay based on Andes hantavirus recombinant nucleoprotein. J Med Microbiol 49: 149-155.

21. López N, Padula P, Rossi C, Miguel S, Edelstein A, Ramírez E,
Franze-Fernández MT, 1997. Genetic characterization and phylogeny of Andes virus and variants from Argentina and Chile. Virus Res 50: 77-84.

22. Felsenstein J, 1993. PHYLIP (Phylogeny Inference Package), version $3.57 c$. Seattle: University of Washington.

23. Powers AM, Mercer DR, Watts DM, Guzman H, Fulhorst CF, Popov VL, Tesh RB, 1999. Isolation and genetic characterization of hantavirus (Bunyaviridae: Hantavirus) from a rodent, Oligoryzomys microtis (Muridae), collected in northeastern Peru. Am J Trop Med Hyg 61: 92-98.

24. Childs JE, Ksiazek TG, Spiropoulou CF, Krebs JW, Morzunov S, Maupin GO, Gage KL, Rollin PE, Sarisky J, Enscore RE, Frey JK, Peters CJ and Nichol ST, 1994. Serologic and genetic identification of Peromyscus maniculatus as the primary rodent reservoir for a new hantavirus in the southwestern United States. J Infect Dis 169: 1271-1280.

25. Dearing MD, Mangione AM, Karasov WH, Morzunov S, Otteson E, St Jeor S, 1998. Prevalence of hantavirus in four species of Neotoma from Arizona and Utah. J Mammalogy 79: 12541259.

26. Monroe MC, Morzunov SP, Johnson AM, Bowen MD, Artsob H, Yates T, Peters CJ, Rollin PE, Ksiazek TG, Nichol ST, 1999. Genetic diversity and distribution of Peromyscus-borne hantaviruses in North America. Emerg Infect Dis 5: 75-86. 